\title{
Corrigendum: Different Patterns of Ecological Divergence Between Two Tetraploids and Their Diploid Counterpart in a Parapatric Linear Coastal Distribution Polyploid Complex
}

\author{
Mariana Castro $^{1 *}$, João Loureiro ${ }^{1}$, Albano Figueiredo ${ }^{2}$, Miguel Serrano ${ }^{3}$, \\ Brian C. Husband ${ }^{4}$ and Sílvia Castro ${ }^{1}$ \\ ${ }^{1}$ Centre for Functional Ecology, Department of Life Sciences, University of Coimbra, Coimbra, Portugal, ${ }^{2}$ Centre for Studies \\ in Geography and Spatial Planning, Department of Geography and Tourism, Faculty of Arts and Humanities, University of \\ Coimbra, Coimbra, Portugal, ${ }^{3}$ Department of Botany, Faculty of Pharmacy, University of Santiago de Compostela, Santiago \\ de Compostela, Spain, ${ }^{4}$ Department of Integrative Biology, University of Guelph, Guelph, ON, Canada
}

Keywords: parapatric distribution, cryptic diversity, diploids, Jasione maritima, niche modeling, tetraploids

\section{A Corrigendum on}

OPEN ACCESS

Approved by:

Frontiers Editorial Office,

Frontiers Media SA, Switzerland

${ }^{*}$ Correspondence: Mariana Castro

mcastro@uc.pt

Specialty section: This article was submitted to Plant Systematics and Evolution,

a section of the journal

Frontiers in Plant Science

Received: 21 April 2020 Accepted: 29 April 2020 Published: 02 June 2020

Citation:

Castro M, Loureiro J, Figueiredo A, Serrano M, Husband BC and Castro $S$

(2020) Corrigendum: Different Patterns of Ecological Divergence Between Two Tetraploids and Their Diploid Counterpart in a Parapatric Linear Coastal Distribution Polyploid Complex. Front. Plant Sci. 11:676. doi: 10.3389/fp/s.2020.00676
Different Patterns of Ecological Divergence Between Two Tetraploids and Their Diploid Counterpart in a Parapatric Linear Coastal Distribution Polyploid Complex

by Castro, M., Loureiro, J., Figueiredo, A., Serrano, M., Husband, B. C., and Castro, S. (2020). Front. Plant Sci. 11:315. doi: 10.3389/fpls.2020.00315

In the original article, we neglected to include the grant number "UID/BIA/04004/2020" for the Portuguese Foundation for Science and Technology (FCT). The corrected Funding statement appears below.

\section{FUNDING}

This research was supported by POPH/FSE funds by the Portuguese Foundation for Science and Technology (FCT) with a doctoral grant to MC (SFRH/BD/89910/2012), a starting grant and exploratory project to SC (IF/01267/2013) and the project UID/BIA/04004/2020, by Xunta de Galicia with the grant to MS (ED431B 2018/36), and by Project RENATURE financed by the "Programa Operacional Regional do Centro 2014-2020 (Centro2020) - CENTRO-01-0145FEDER-000007”.

The authors apologize for this error and state that this does not change the scientific conclusions of the article in any way. The original article has been updated.

Copyright $(2020$ Castro, Loureiro, Figueiredo, Serrano, Husband and Castro. This is an open-access article distributed under the terms of the Creative Commons Attribution License (CC BY). The use, distribution or reproduction in other forums is permitted, provided the original author(s) and the copyright owner(s) are credited and that the original publication in this journal is cited, in accordance with accepted academic practice. No use, distribution or reproduction is permitted which does not comply with these terms. 